\title{
FERRARI, Marcela y MELLADO, Virginia (Comps.), (2016), La Renovación peronista: organización partidaria, liderazgos y di- rigentes, 1983-1991. Caseros: EDUNTREF. 334 pp.
}

Ernesto Roland ${ }^{1}$

Hacia mediados de los años ochenta la Renovación Peronista (RP) se constituyó en el principal vector de cambio interno del peronismo y en uno de los actores más dinámicos de la política nacional. Este libro enriquece los estudios existentes al abordar la RP desde un enfoque subnacional, efectuar una descripción densa de las prácticas políticas e incorporar un conjunto de fuentes hasta ahora desatendidas (periódicos provinciales, fuentes judiciales y testimonios orales, entre otras). Esta obra colectiva parte de la pregunta por las características de la RP en diversos distritos del PJ (ocho provincias y Capital Federal), y por los cambios que esta corriente trajo en la organización partidaria. La RP impulsó una democratización del Partido Justicialista (PJ), vía elecciones internas donde los afiliados pudieran elegir las autoridades partidarias y las candidaturas electorales. También bregó por un cambio en las prácticas, ideas y estilos de la dirigencia justicialista. Se sabe que los años ochenta presentan un conjunto de modificaciones novedosas para la historia política argentina. Este libro puede considerarse un aporte en torno al procesamiento de estas modificaciones por parte de un actor clave: el peronismo.

En el capítulo uno, Marcela Ferrari y Virginia Mellado historizan las diversas interpretaciones sobre la RP y, en base a ello, presentan las coordenadas teóricas y metodológicas que fundamen$\tan$ las investigaciones del libro. El enfoque subnacional propuesto se justifica por las características del objeto. La reconstrucción democrática recupera un sistema federal de gobierno que asigna un peso significativo a los estados provinciales. A su vez, el PJ nacional carecía para entonces de una coalición dirigente legítima, lo que estimulaba a la dirigencia a posicionarse en las provincias. Para ello se apoyaban en el carácter descentralizado del PJ, un partido nacional de distritos. Por otra parte, el enfoque subnacional presenta un atractivo heurístico. Siguiendo a Macor y Tcach, se considera a las provincias como espacios de producción de lo político. Las organizaciones, los estilos, las prácticas y las culturas políticas varían considerablemente de una provincia a otra y ello se examina en clave de «reconstrucción democrática», para así recuperar «las incertidumbres, las ten-

\footnotetext{
${ }^{1}$ Profesor en Historia por la Facultad de Filosofía y Humanidades y Maestrando en Partidos Políticos por el Centro de Estudios Avanzados de la Facultad de Ciencias Sociales de la Universidad Nacional de Córdoba. Contacto: choloroland@gmail.com
} 
siones y los conflictos propios del período» (2016: 35 ).

Los capítulos comparten un conjunto de dimensiones de análisis. Dan cuenta del modo en el que se implementó la elección directa en cada distrito; la relación entre este mecanismo y la configuración de nuevas coaliciones dominantes (ya se para ejercer el mandato provincial, como para constituir una oposición competitiva); las especificidades a la hora de incorporar nuevas prácticas y su coexistencia con elementos tradicionales; así como la relación y los márgenes de autonomía de los distritos respecto de las vicisitudes nacionales.

La RP en Mendoza es estudiada por Virginia Mellado. La autora analiza los recorridos y prácticas de una nueva camada de dirigentes identificados con la $\mathrm{RP}$, destacando la temprana inserción territorial del partido, la búsqueda del «voto independiente» a partir de estudios de opinión y el retroceso del poder de los sindicalistas. Da cuenta también de las redes de sociabilidad que permitieron a Bordón liderar la RP en Mendoza.

Norma Álvarez toma el caso de Misiones. Partiendo de una caracterización de la economía local, la autora destaca que el sindicalismo tradicionalmente tuvo poco peso en las decisiones partidarias. En el nuevo marco, fue determinante el liderazgo de Humada y la pervivencia de prácticas informales para la elección de candidatos. Una vez consolidada la hegemonía humadista, se obstaculizó la oposición y el debate interno.

Cintia Rodrigo señala que el peronismo de San Juan pudo resolver sus conflictos mediante mecanismos institucionales. Allí primó una disputa entre renovadores. El sector sindical osciló entre la disputa interna, aggiornándose con motivos de la RP, y la alianza con un rival y competidor del PJ local, el bloquismo.

Adriana Kindgard señala que en la transición democrática en Jujuy se expresa un anticipo de la RP liderada por De Aparici. Aquí la disidencia se produce con caudillos tradicionales. Desde un aporte explicativo de Silvia Sigal, Kindgard dilucida la gravitación de la tradición populista clásica en el «verticalista» Martiarena.

Marcelino Maina señala que el peronismo de Santa Fe de los ochenta no logró consolidar una coalición dominante, ya que primó una disputa por posiciones partidarias y una marcada dispersión territorial. Los alineamientos con el plano nacional fueron erráticos y cambiantes. Los comicios directos internos no lograron estabilizar al peronismo santafecino.

Gabriela Closa apunta que la RP en Córdoba impulsó una «doble batalla», buscando consolidar una nueva coalición dominante, y pretendiendo competir con la fuerza hegemónica, la UCR. La incapacidad de reorganizar el distrito, los reveses electorales y la postergación de las elecciones internas, agudizaron el enfrentamiento del sector tradicional con la RP liderada por De La Sota. La RP mediterránea buscó dotar al PJ de una nueva imagen, tomando distancia de la conflictiva experiencia de gobierno de los setenta.

Según Osvaldo Luoni, el PJ de la ciudad de Buenos Aires era una estructura radial, caracterizada por la descon- 
centración en subunidades. El líder de la RP, Grosso, merced a su inserción en el electorado independiente y a su capacidad de recurrir a fuentes de financiamiento externas al partido, pudo coordinar estratégicamente a las distintas fracciones. Sin embargo, la RP no logró una cohesión sólida del justicialismo porteño.

Aixa Bona y Juan Vilaoba reconstruyeron la RP en Santa Cruz. Aquí también se percibe un peso escaso del sector sindical y la ausencia de tensiones heredadas de los setenta. No obstante, se produjeron múltiples conflictos entre la RP, el gobernador Puricelli y el sector liderado por Kirchner.

Marcela Ferrari estudió la RP en la provincia de Buenos Aires. La autora examina las prácticas y estrategias de la $\mathrm{RP}$ en su conflicto con la ortodoxia. Puede observarse el modo en el que la dinámica nacional repercute aquí, al ser un distrito central para las elecciones nacionales. Una vez desplazada la conducción «herminista», la RP liderada por Cafiero encuentra un nuevo adversario nucleado bajo el proyecto presidencial de Menem, quien aglutina al sector sindical desplazado y una fracción territorial de la RP liderada por Duhalde.

El libro permite apreciar que la interna justicialista adoptó mayor voltaje ideológico y confrontación en los distritos más supeditados a la estructura nacional, reactualizando por momentos tensiones de los años setenta, y resultó más ambigua e indefinida en los distritos restantes. Ello se relaciona con la reticencia de la fracción que controlaba el Consejo Nacional Justicialista (CNJ) a introducir el voto directo de los afilia- dos. En Capital Federal la nueva metodología se implementó recién en 1986, y en provincia de Buenos Aires, el interventor del CNJ dilató el proceso electoral hasta fines de ese año, a efectos de reagrupar a los sectores enfrentados con la RP y volcarlos al proyecto de Menem. En cambio, las elecciones directas se introdujeron hacia fines de 1984 en Misiones, $\mathrm{y}$ al año siguiente en Mendoza, San Juan, Santa Fe y Santa Cruz, distritos que ganaron autonomía respecto de la dinámica nacional. El voto directo tuvo que esperar hasta 1986 en Jujuy y 1987 en Córdoba, pero allí la dilación se relaciona con la especificidad de ambos distritos.

El voto directo no siempre logró ser un mecanismo eficaz para canalizar los conflictos internos, como lo muestra el caso santafecino, jujeño y santacruceño, ni garantizó per se la constitución de una coalición dominante estable, como se observa en Capital Federal. También se pone de relieve como el «momento renovador» introduce un vínculo novedoso entre los peronismos provinciales y el mundo empresarial. La RP jujeña impulsó una alianza con profesionales e industriales de la UIA local; en Córdoba el PJ incorpora como candidato a diputado nacional en 1987 al economista de la Fundación Mediterránea Cavallo; y en Misiones Humada priorizó la vinculación con el empresario yerbatero Ramón Puerta. Los ochenta también despuntan nuevas estrategias para captar el «voto independiente» en elencos provinciales como el de Mendoza y Córdoba, desplazando la apelación de símbolos e ideas tradicionales en el peronismo.

El libro concluye con una síntesis y 
reflexión general de María Teresa Bra- sobre el desempeño del peronismo en chetta. Para la autora una comparación la democracia reciente. De allí que una de casos subnacionales permite una mirada de mayor alcance sobre esta fuermayor comprensión de la coyuntura de za debe dar cuenta de los cambios que los años ochenta y abre interrogantes trajo esta época. 